\title{
Development of Mathematical Model for Cassava Starch Properties Using Response Surface Methodology
}

\author{
T. Krishnakumar ${ }^{1 *}$. M. S. Sajeev ${ }^{1}$, Namrata A. Giri ${ }^{1}$, Chintha Pradeepika ${ }^{1}$ and \\ Venkatraman Bansode ${ }^{2}$ \\ ${ }^{1}$ Division of Crop Utilization, ICAR-Central Tuber Crops Research Institute (CTCRI), \\ Thiruvananthapuram, Kerala - 695 017, India \\ ${ }^{2}$ ICAR-Central Tuber Crops Research Institute (CTCRI), Regional Centre, Bhubaneswar, \\ Odisha - 751019, India \\ *Corresponding author
}

\begin{abstract}
A B S T R A C T
The objective of this present study was to obtain optimized conditions for calculating cassava starch properties using response surface methodology (RSM). In this study, Box-

\begin{tabular}{|l|}
\hline Ke y w or d s \\
Cassava starch, \\
Ultrasound, Functional \\
properties, Polynomial \\
model, RSM \\
\hline Article Info \\
\hline Accepted: \\
22 July 2019 \\
Available Online: \\
10 August 2019 \\
\hline
\end{tabular}
Behnken response surface design (BBD) was used to optimize cassava starch properties (3 independent process factors at 3 levels with 17 runs) and to evaluate the main, linear and combined effects of cassava starch extraction conditions. The independent process variables selected in this study were sonication temperature $\left(30,40,50^{\circ} \mathrm{C}\right)$, sonication time $(10,20,30 \mathrm{~min})$ and solid-liquid ratio $(1: 10,1: 20,1: 30 \mathrm{~g} / \mathrm{ml})$. The non-linear second order polynomial quadratic regression model was used for experimental data to determine the relationship between the independent process variables and the responses (clarity of starch, freeze-thaw stability, Total colour difference, whiteness index, solubility index, swelling power). Design Expert software (version 10.0.2.0) was used for regression analysis and Pareto analysis of variance (ANOVA). The optimal conditions based on both individual and combinations of all independent variables (sonication temp of $50^{\circ} \mathrm{C}$, sonication time of $30 \mathrm{~min}$, solid-liquid ratio of $1: 16.7 \mathrm{~g} / \mathrm{ml}$ ) were measured with maximum CS of $27.04 \%$, FT of $77.73 \%$, WI of $93.47 \%$, SOL of $1.35 \%$ and SP of $3.17 \mathrm{~g} / \mathrm{g}$ with a desirability value of 0.669 , which was confirmed through validation experiments.
\end{abstract}

\section{Introduction}

Cassava (Manihot esculenta Crantz) is an important staple food as well as industrial crop in Asia, Africa and Latin America. It is considered as the cheapest source of carbohydrate among cereals, tubers and root crops and also branded as the poor man's crop in rural areas. In India, it is cultivated in an area of 0.20 million hectares with a total production of 8.13 million tonnes (Krishnakumar and Sajeev, 2018). It can be used as a raw material for a number of value added industrial products such as starch, sago, liquid glucose, dextrin, gums and high fructose syrup (Krishnakumar and Sajeev, 2017). Native starches from cassava are now widely used as food ingredient for production 
of seasoning powder, sauces, glucose and bakery products (Sheriff et al., 2005). Native starches are to be modified to improve their functional properties in order to meet the requirement for various uses. Among different physical, chemical and enzymatic techniques, chemical modification is most important and widely used. Recent years, physical modification of starches are gaining more attention due to less amount of byproducts and chemical agents thus this technique more sustainable and environment friendly (Vroman and Tighzert, 2016).

Ultrasonication is a physical process that uses ultrasound energy with frequency higher than the threshold of human hearing (Jambrak et al., 2010; Krishnakumar et al., 2016). Ultrasound is a sound waves having frequency above the threshold of human hearing (20 $\mathrm{kHz}$ ). It causes acoustic cavitation which is the phenomenon of generation, growth and collapse of bubbles (Zhu, 2015). It finds useful to modify the functionality of starch in terms of physico-chemical and functional properties. Response surface methodology (RSM) comprises of a number of methods for finding optimal conditions through experimental methods.

It is an efficient optimization technique and combination of statistical and mathematical calculations, requires a less number of experimental runs for process optimization (Talebpour et al., 2009, Yuan et al., 2015).

It is used as an important tool to analyze the interaction between variables and measure the effect of variables on responses (Li et al., 2006; Hatambeygi et al., 2011; Ma et al., 2016). Thus the objective of this study was to examine the effects of different sonication temperature, sonication time and solid-liquid ratio on the important cassava starch properties using response surface methodology (RSM).

\section{Materials and Methods}

\section{Raw materials}

Matured cassava (Manihot esculenta) variety of Sree Pavithra was obtained from the ICARCTCRI research farm for starch extraction and ultrasonication studies.

\section{Isolation of starch}

The separation of starch granules from cassava tuber in a pure form is essential in the manufacture of cassava starch. The cassava starch was extracted from the fresh cassava tubers by the methods described earlier (Krishnakumar and Sajeev, 2018).

\section{Ultrasonication treatment}

Ultrasound treatment (US) for cassava starch was conducted according to the method of ying et al., (2011), using a probe ultrasonicator (Sonic, Model: VCX750) operating frequency of $30 \pm 3 \mathrm{kHz}$, input voltage of $230 \mathrm{~V}$ and heating strength of 750 $\mathrm{W}$, attached with digital timer. The aqueous cassava starch suspension obtained from the isolated cassava starch were treated with a constant ultrasound power of $750 \mathrm{~W}$ and $50 \%$ amplitude during different sonication temperature $\left(30,40,50^{\circ} \mathrm{C}\right)$, sonication time (10, 20, $30 \mathrm{~min})$, solid-liquid ratio (1:10, 1:20, $1: 30 \mathrm{~g} / \mathrm{ml})$.

Ultrasonic probe of $19 \mathrm{~mm}$ diameter was directly placed in the suspension (cassava mash + distilled water) at a depth of $28 \mathrm{~mm}$ from the suspension surface and the desired amplitude (\%) and extraction time (min) were maintained by means of digital amplitude and time controller. After the treatment, the pure starch was dried, powdered using pestle and mortar, sieved through standard BSS 100 mesh sieve and then stored in airtight container for further analysis. 


\section{Clarity of starch}

The clarity of ultrasound treated cassava starch sample was measured using the method described by Sandhu and Singh (2007). Aqueous starch suspension containing 1\% (w/v) of starch was prepared by heating $0.2 \mathrm{~g}$ starch in $20 \mathrm{ml}$ water in a shaking water bath at $90^{\circ} \mathrm{C}$ for $1 \mathrm{~h}$. The starch paste was cooled to room temperature and the transmittance was measured at $640 \mathrm{~nm}$ in a UV spectrophometer (Spectra scan uv-2600, Thermo fisher scientific, India).

\section{Freeze-Thaw stability}

Freeze-thaw stability was determined according to the method of Singhal and Kulkarni (1990). Ultrasonicated (US) starch at a concentration of $5 \%(\mathrm{w} / \mathrm{v})$ was heated in distilled water at $95^{\circ} \mathrm{C}$ for $30 \mathrm{~min}$ with constant stirring. Ten milliliters of paste was transferred into the weighed centrifuge tube. This was subjected to alternate freezing and thawing cycles $\left(22 \mathrm{~h}\right.$ freezing at $-20^{\circ} \mathrm{C}$ followed by $2 \mathrm{~h}$ thawing at $30^{\circ} \mathrm{C}$ ) for 3 days and centrifuged at $5000 \times \mathrm{g}$ for $10 \mathrm{~min}$ after each cycles. The percentage (\%) of syneresis was then calculated as the ratio of the weight of the liquid decanted and the total weight of the gel before centrifugation multiplied by 100. Totally three freeze-thaw cycles were conducted for each sample.

\section{Colour of starch}

The colour of the US starch sample was analyzed using a colorimeter (Hunter Lab, Virginia). The primary colour parameters 'L','a','b' were measured by placing samples in the sample holder. The ' $L$ ' parameter represent light dark spectrum with a range from 0 (black) to 100 (white), 'a' represents green red spectrum ranging from -60 (green) to +60 (red) and ' $b$ ' represents blue yellow spectrum with a range from -60 (blue) to +60 (yellow) dimensions respectively. From the primary coordinates, total colour difference (TCD) and whiteness index (WI) were calculated using standard equations as explained by CIE (1986).

$$
\begin{aligned}
& \mathrm{TCD}=\left[\left(\mathrm{L}_{0}-\mathrm{L}\right)^{2}+\left(\mathrm{a}_{0}-\mathrm{a}\right)^{2}+\left(\mathrm{b}_{0}-\mathrm{b}\right)^{2}\right]^{0.5} \\
& \mathrm{WI}=100-\left[(100-\mathrm{L})^{2}+\mathrm{a}^{2}+\mathrm{b}^{2}\right]^{0.5}
\end{aligned}
$$

Where, $\mathrm{L}_{0}=99.34, \mathrm{a}_{0}=0, \mathrm{~b}_{0}=0$ reading of the calibreation plate (white)

\section{Solubility and swelling power}

Solubility index (\%) of the cassava starch was determined using Ding et al., (2006). The 2.5 $\mathrm{g}$ of cassava starch was weighed into $50 \mathrm{ml}$ centrifuge tube and heated in $30 \mathrm{ml}$ distilled water in a water bath at $60^{\circ} \mathrm{C}$ for $30 \mathrm{~min}$ without mixing and then centrifuged at 3000 $\mathrm{rpm}$ for $10 \mathrm{~min}$. The supernatant was dried at $105^{\circ} \mathrm{C}$ to constant weight and the weight of the dry solids was measured. All the experiments were made in triplicate. The following equation used to calculate the solubility index.

$$
\text { Solubility index }(\%)=\frac{m_{s}}{m_{d}} \times 100
$$

Where,

$\mathrm{m}_{\mathrm{s}}$ - Weight of soluble starch $(\mathrm{g})$

$\mathrm{m}_{\mathrm{d}}$ - Weight of starch sample on dry basis $(\mathrm{g})$

Swelling power $(\mathrm{g} / \mathrm{g})$ was determined by modified method of Betancur et al., (2001). $2.5 \mathrm{~g}$ of the ultrasonicated cassava starch sample was weighed into $50 \mathrm{ml}$ centrifuge tube. Then $30 \mathrm{ml}$ of distilled water was added and mixed gently. The sample was heated in a water bath at $60^{\circ} \mathrm{C}$ for $30 \mathrm{~min}$ and centrifuged at $3000 \mathrm{rpm}$ for $10 \mathrm{~min}$. The supernatant was 
decanted immediately after centrifuging. The weight of the sediment was taken and recorded.

Swelling power $(\mathrm{g} / \mathrm{g})=$

Weight of sedimented starch paste (g)

Weight of starch sample on dry basis x (100-\% solubility

\section{Experimental design}

Response surface methodology (RSM) is reported to be an efficient tool for optimizing a process when the independent variable has a joint effect on the responses. In RSM, BoxBehnhen design (BBD) is an efficient response surface design for fitting second order polynomials to response surfaces. Thus, BBD design methodology was adopted in this study to examine and optimize the effect of three independent process variables with three levels (sonication temperature $\left(30-50^{\circ} \mathrm{C}\right)$, sonication time $(10-30 \mathrm{~min})$ and solid to solvent ratio $(1: 10$ to $1: 30 \mathrm{~g} / \mathrm{ml})$ on different properties (optical clarity, freeze-thaw stability, TCD, WI, solubility index and swelling power) of the cassava starch (Table 1). From the preliminary experiments on single factor test, levels for independent experimental process variables were selected. It consisted of 17 experiments with 5 central points for estimating experimental error. The total number of experiments $(\mathrm{N})$ for this study was measured using the eq. (2).

$\mathrm{N}=2 \mathrm{~F}(\mathrm{~F}-1)+\mathrm{P}_{1}$

Where, $\mathrm{F}$ is number of variables; $\mathrm{P}_{1}$ is the replicate number of centre points.

For statistical measurements, the process independent variables were coded with three levels between $-1,0$ and +1 and the coding was performed by using the eq. (3).
$Y_{i}=\frac{y_{i}-y_{z}}{\Delta y_{i}} \quad i=1,2,3, \ldots \ldots \ldots \ldots \ldots \ldots \ldots \ldots \ldots k$

The generalized form of the non-linear quadratic second order polynomial response model is presented in the eq. (4).

$\operatorname{Response}(\mathrm{Y})=\beta_{0}+\sum_{\mathrm{j}=1}^{\mathrm{k}} \beta_{\mathrm{j}} \mathrm{X}_{\mathrm{j}}+\sum_{\mathrm{j}=1}^{\mathrm{k}} \beta_{\mathrm{jj}} \mathrm{X}_{\mathrm{j}}^{2}+\sum_{\mathrm{i}} \sum_{<\mathrm{j}=2}^{\mathrm{k}} \beta_{\mathrm{ij}} \mathrm{X}_{\mathrm{i}} \mathrm{X}_{\mathrm{j}}$

Where $\mathrm{Y}$ indicates responses; $X_{i}$ and $X_{j}$ denotes process independent variables ( $\mathrm{i}$ and $\mathrm{j}$ range from 1 to $\mathrm{k}$ ) and $\beta_{0}$ represents interception coefficient of regression model; $\beta_{\mathrm{j}}, \beta_{\mathrm{jj}}, \beta_{\mathrm{ij}}$ are linear, quadratic and interaction coefficients; $k$ indicates the number of independent process variables $(\mathrm{k}=3)$.

\section{Determination of desirability and validation of optimized conditions}

Optimization of multiple responses for various independent process variables is performed by derringer desirability function (Derringer and Suich, 1980). This is one of the most widely used techniques for multi response optimization. In this technique, the predicted response (starch yield) is transformed into a dimensionless partial desirability function $\left(\mathrm{g}_{i}\right)$, which varies from 0 to 1 . The required goals of response and independent process variables were chosen. For maximizing the response, the independent process variables were kept within range, where the response was maximized with the help of desirability function (D).

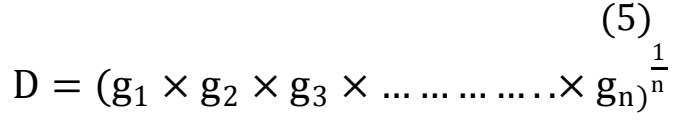

Where, $\mathrm{g}_{\mathrm{i}}$ is desirability of response; $\mathrm{n}$ is number of responses. If any one of the variable response is outside the desirability, the total function will be converted into $0 . \mathrm{g}_{\mathrm{i}}$ ranges between completely undesired response to fully desired response (0 to 1$)$. The 
maximization and transformation of response into a multi-response dimensionless desirability $\left(\mathrm{T}_{\mathrm{i}}\right.$ ) was done using the eq. (6).

$\mathrm{T}_{\mathrm{i}}=\frac{\mathrm{Z}_{\mathrm{i}}-\mathrm{Z}_{\min }}{\mathrm{Z}_{\max }-\mathrm{Z}_{\min }}$

Where, $Z_{\min }$ is the minimum value of response; $Z_{\max }$ is the maximum value of response; $\mathrm{Z}_{\mathrm{i}}$ is the weight of individual response. Triplicate processing experiments were conducted to confirm the results under the optimal conditions and its mean values were compared with the predicted values at the same conditions to validate the developed regression model.

\section{Statistical analysis}

Experimental data were analyzed by least square method of multiple regression analysis. Pareto analysis of variance (ANOVA) at $95 \%$ level of confidence $(p<0.05)$ was applied to calculate linear, quadratic and interaction coefficients of regression model so as to measure the significance of process variables. $\mathrm{F}$-value and predicted $\mathrm{R}^{2}$ was considered to check model adequacy. RSM was applied using Design Expert statistical package version 10.0.2.0 (Stat Ease Inc., Minneapolis, $\mathrm{MN}$, USA) to determine the optimal responses.

\section{Results and Discussion}

\section{Box-Behnken analysis}

Experiments were conducted so as to study the linear, cubic, quadratic and interaction effect of independent process variables (sonication power, sonication time and solid to solvent ratio) on the properties (optical clarity, freezethaw stability, TCD, WI, solubility index, swelling power) and the results are listed in of the cassava starch and the measures responses are presented in Table 2. The experimental data were fitted to various polynomial models viz., linear, interactive (2FI), quadratic and cubic models. To calculate the suitability models for starch properties two different statistical tests were performed viz.9sequential model sum of squares and model statistics in the present study and the results are presented in the Table 3 . The analyzed parameters are presented in Table 3. The results showed that quadratic model was statistically highly significant and showed higher value of $\mathrm{R}^{2}$, adjusted $\mathrm{R}^{2}$ and predicted $\mathrm{R}^{2}$ and also exhibited a low $p$-value (Table 3 ). The fit summary of the output indicates that the quadratic model found to statistically significant and the $\mathrm{p}$ value was lower than 0.001. Cubic was found to be aliased.

\section{Fitting of non-linear quadratic polynomial model and statistical analysis}

The second order polynomial equation was fitted with experimental results obtained on the basis of Box-Behnken experimental design. Six empirical models were developed to understand the interaction correlation between the responses and process variables. The predicated final equation obtained in terms of coded factors is presented below.

Analysis of variance (ANOVA) and the model regression coefficients for the experimental data were compared by their corresponding $p$ values mentioned in the Table 4 and it indicated that the equation adequately represented the actual relationship between the response (OC, FT, TCD, WI, SOL, SP) and their significant values. The ANOVA table also shows a term for residual error, which measures the amount of variation in the response data left unexplained by the model. The low predicted $\mathrm{R}^{2}$ compared to fitted $\mathrm{R}^{2}$, implies that the model as fitted is adequate to predict. The model gives regression coefficient $\left(\mathrm{R}^{2}\right)$ values of 0.910 for $\mathrm{OC}, 0.918$ for FT, 0.908 for TCD, 0.925 for WI, 0.927 
for SOL, 0.947 for SP. The probability $(\sim 0.0002)$ of all response model is less than 0.05 . This indicates the model terms are significant at $95 \%$ of probability level. The OC $(\%)=10.29+2.19 \mathrm{X}_{1}-7.13 \mathrm{X}_{2}+5.78 \mathrm{X}_{3}-10.64 \mathrm{X}_{1} \mathrm{X}_{2}$

$$
+15.84 X_{1} X_{3}+15.96 X_{2} X_{3}-9.48 X_{1}^{2}+12.68 X_{2}^{2}+21.08 X_{3}^{2}
$$

$\mathrm{FT}(\%)=56.22+0.079 \mathrm{X}_{1}+5.92 \mathrm{X}_{2}+3.25 \mathrm{X}_{3}+18.70 \mathrm{X}_{1} \mathrm{X}_{2}$

$$
+4.49 \mathrm{X}_{1} \mathrm{X}_{3}-11.56 \mathrm{X}_{2} \mathrm{X}_{3}-0.019 \mathrm{X}_{1}^{2}-2.40 \mathrm{X}_{2}^{2}-18.44 \mathrm{X}_{3}^{2}
$$

$$
\begin{aligned}
\operatorname{TCD}(\%)= & 3.39-0.055 \mathrm{X}_{1}+0.15 \mathrm{X}_{2}-0.66 \mathrm{X}_{3}+0.24 \mathrm{X}_{1} \mathrm{X}_{2} \\
& +0.37 \mathrm{X}_{1} \mathrm{X}_{3}-0.16 \mathrm{X}_{2} \mathrm{X}_{3}+0.070 \mathrm{X}_{1}^{2}+0.012 \mathrm{X}_{2}^{2}+0.48 \mathrm{X}_{3}^{2}
\end{aligned}
$$

$$
+1.27 X_{1}-0.77 X_{2} X_{3}-0.24 X_{1}^{2}+0.65 X_{2}^{2}+1.46 X_{3}^{2}
$$

$$
\begin{aligned}
\mathrm{SP}(\mathrm{g} / \mathrm{g})= & 1.91+0.022 \mathrm{X}_{1}+0.024 \mathrm{X}_{2}+0.026 \mathrm{X}_{3}-0.005 \mathrm{X}_{1} \mathrm{X}_{2} \\
& -0.030 \mathrm{X}_{1} \mathrm{X}_{3}-0.032 \mathrm{X}_{2} \mathrm{X}_{3}+0.016 \mathrm{X}_{1}^{2}-0.032 \mathrm{X}_{2}^{2}-0.042 \mathrm{X}_{3}^{2}
\end{aligned}
$$


Table.1 Box behnken design matrix with coded and uncoded values of the independent variables and their levels

\begin{tabular}{|c|c|c|c|}
\hline Run order & $\begin{array}{c}\text { Sonication temperature } \\
\left(\mathbf{X}_{\mathbf{1}} \mathbf{}^{\circ} \mathbf{C}\right)\end{array}$ & $\begin{array}{c}\text { Sonication time } \\
\left(\mathbf{X}_{\mathbf{2}}, \mathbf{m i n}\right)\end{array}$ & $\begin{array}{c}\text { Solid-liquid ratio } \\
\left(\mathbf{X}_{\mathbf{3}}, \mathbf{g} / \mathbf{m l}\right)\end{array}$ \\
\hline $\mathbf{1}$ & $40(0)$ & $20(0)$ & $1: 20(0)$ \\
\hline $\mathbf{2}$ & $50(1)$ & $10(-1)$ & $1: 20(0)$ \\
\hline $\mathbf{3}$ & $40(0)$ & $20(0)$ & $1: 20(0)$ \\
\hline $\mathbf{4}$ & $40(0)$ & $30(1)$ & $1: 30(1)$ \\
\hline $\mathbf{5}$ & $30(-1)$ & $10(-1)$ & $1: 20(0)$ \\
\hline $\mathbf{6}$ & $40(0)$ & $10(-1)$ & $1: 30(1)$ \\
\hline $\mathbf{7}$ & $40(0)$ & $20(0)$ & $1: 20(0)$ \\
\hline $\mathbf{8}$ & $40(0)$ & $30(1)$ & $1: 10(-1)$ \\
\hline $\mathbf{9}$ & $50(1)$ & $20(0)$ & $1: 10(-1)$ \\
\hline $\mathbf{1 0}$ & $50(1)$ & $20(0)$ & $1: 10(-1)$ \\
\hline $\mathbf{1 1}$ & $40(0)$ & $20(0)$ & $1: 20(0)$ \\
\hline $\mathbf{1 2}$ & $50(1)$ & $20(0)$ & $1: 10(-1)$ \\
\hline $\mathbf{1 3}$ & $40(0)$ & $10(-1)$ & $1: 20(0)$ \\
\hline $\mathbf{1 4}$ & $40(0)$ & $20(0)$ & $1: 30(1)$ \\
\hline $\mathbf{1 5}$ & $30(-1)$ & $20(0)$ & $1: 20(0)$ \\
\hline $\mathbf{1 6}$ & $30(-1)$ & $30(1)$ & $1: 20(0)$ \\
\hline $\mathbf{1 7}$ & $50(1)$ & $30(1)$ & \\
\hline
\end{tabular}

Table.2 Box-behnken experimental design and observed responses

\begin{tabular}{|c|c|c|c|c|c|c|c|c|c|}
\hline $\begin{array}{c}\text { Run } \\
\text { order }\end{array}$ & $\left(\mathbf{X}_{1}{ }^{\circ} \mathbf{C}\right)$ & $\left(\mathbf{X}_{2}, \min \right)$ & $\left(\mathbf{X}_{3}, \mathrm{~g} / \mathrm{ml}\right)$ & $\begin{array}{c}\text { Clarity } \\
\text { of } \\
\text { starch } \\
(\mathrm{CS}, \%)\end{array}$ & $\begin{array}{l}\text { Freeze } \\
\text { thaw } \\
\text { stability, } \\
\text { (FT, \%) }\end{array}$ & $\begin{array}{l}\text { TCD } \\
(\%)\end{array}$ & WI (\%) & $\begin{array}{c}\text { Solubility } \\
\text { (Sol, \%) }\end{array}$ & $\begin{array}{c}\text { Swelling } \\
\text { power } \\
\text { (SP, g/g) }\end{array}$ \\
\hline 1 & 40 & 20 & $1: 20$ & 8.19 & 56.25 & 5.65 & 93.81 & 0.40 & 3.38 \\
\hline 2 & 50 & 10 & $1: 20$ & 13.20 & 38.59 & 5.31 & 94.15 & 0.80 & 3.52 \\
\hline 3 & 40 & 20 & $1: 20$ & 8.20 & 56.18 & 5.66 & 93.81 & 0.40 & 3.38 \\
\hline 4 & 40 & 30 & $1: 30$ & 7.61 & 44.80 & 5.65 & 93.80 & 0.80 & 3.46 \\
\hline 5 & 30 & 10 & $1: 20$ & 8.46 & 65.72 & 6.23 & 93.24 & 0.80 & 3.44 \\
\hline 6 & 40 & 10 & $1: 30$ & 6.29 & 38.79 & 6.25 & 93.21 & 0.40 & 3.50 \\
\hline 7 & 40 & 20 & $1: 20$ & 8.21 & 56.19 & 5.65 & 93.82 & 0.41 & 3.39 \\
\hline 8 & 40 & 30 & $1: 10$ & 21.66 & 27.75 & 7.95 & 91.50 & 1.20 & 3.26 \\
\hline 9 & 50 & 20 & $1: 10$ & 5.76 & 63.55 & 8.73 & 90.72 & 1.60 & 3.12 \\
\hline 10 & 50 & 20 & $1: 10$ & 12.68 & 37.25 & 5.93 & 93.53 & 2.80 & 3.15 \\
\hline 11 & 40 & 20 & $1: 20$ & 8.18 & 56.23 & 5.65 & 93.80 & 0.39 & 3.38 \\
\hline 12 & 50 & 20 & $1: 30$ & 4.49 & 32.99 & 4.58 & 94.89 & 0.80 & 3.66 \\
\hline 13 & 40 & 10 & $1: 10$ & 11.65 & 39.72 & 8.17 & 91.30 & 0.80 & 3.25 \\
\hline 14 & 40 & 20 & $1: 20$ & 8.19 & 56.25 & 5.64 & 93.81 & 0.40 & 3.39 \\
\hline 15 & 30 & 20 & $1: 30$ & 10.49 & 42.72 & 5.52 & 93.93 & 0.40 & 3.48 \\
\hline 16 & 30 & 30 & $1: 20$ & 17.97 & 31.61 & 5.83 & 93.83 & 1.20 & 3.39 \\
\hline 17 & 50 & 30 & $1: 20$ & 30.12 & 79.29 & 6.30 & 94.46 & 0.80 & 3.19 \\
\hline
\end{tabular}


Table.3 Sequential model sum of squares and model summary statistics for the responses

\begin{tabular}{|c|c|c|c|c|c|c|c|c|c|}
\hline Source & Sum of square & Mean square & DF & F value & Prob $>\mathbf{F}$ & $\mathbf{R}^{2}$ & Adjusted $\mathbf{R}^{2}$ & Predicted $\mathbf{R}^{2}$ & Remarks \\
\hline \multicolumn{10}{|c|}{ Clarity of starch $(\%)$} \\
\hline Mean & 2154.11 & 2151.11 & 1 & & & & & & \\
\hline Linear & 243.65 & 81.22 & 3 & 2.40 & 0.1152 & 0.356 & 0.207 & 0.198 & \\
\hline $2 \mathrm{FI}$ & 36.88 & 12.29 & 3 & 0.30 & 0.8216 & 0.560 & 0.416 & 0.402 & \\
\hline Quadratic & 243.53 & 81.18 & 3 & 4.55 & 0.0005 & 0.910 & 0.892 & 0.865 & Suggested \\
\hline Cubic & 136.24 & 68.12 & 2 & 14.23 & 0.0086 & 0.965 & 0.888 & 0.876 & Aliased \\
\hline Residual & 23.94 & 4.79 & 5 & & & & & & \\
\hline Total & 2838.35 & 166.96 & 17 & & & & & & \\
\hline \multicolumn{10}{|c|}{ Freeze-thaw stability (\%) } \\
\hline Mean & 39928.13 & 39928.13 & 1 & & & & & & \\
\hline Linear & 31.45 & 10.48 & 3 & 0.043 & 0.9874 & 0.009 & -0.218 & -1.013 & \\
\hline 2 FI & 1529.88 & 509.96 & 3 & 3.17 & 0.0722 & 0.492 & 0.188 & -1.134 & \\
\hline Quadratic & 1233.27 & 411.09 & 3 & 7.69 & 0.0003 & 0.918 & 0.896 & 0.875 & Suggested \\
\hline Cubic & 28.22 & 14.11 & 2 & 0.20 & 0.8219 & 0.890 & 0.650 & 0.631 & Aliased \\
\hline Residual & 345.85 & 69.17 & 5 & & & & & & \\
\hline Total & 43096.80 & 2535.11 & 17 & & & & & & \\
\hline \multicolumn{10}{|l|}{ TCD $(\%)$} \\
\hline Mean & 540.09 & 540.09 & 1 & & & & & & \\
\hline Linear & 0.89 & 0.02 & 3 & 4.64 & 0.0064 & 0.436 & 0.342 & 0.163 & \\
\hline 2 FI & 0.36 & 0.06 & 3 & 1.35 & 0.2880 & 0.611 & 0.395 & -0.081 & \\
\hline Quadratic & 0.79 & 0.20 & 3 & 582.33 & 0.0004 & 0.908 & 0.895 & 0.887 & Suggesetd \\
\hline Cubic & 0.00 & 0.00 & 2 & 2.90 & 0.1059 & 1.000 & 0.998 & 0.931 & Aliased \\
\hline Residual & 0.00 & 0.00 & 5 & & & & & & \\
\hline Total & 542.13 & 18.69 & 17 & & & & & & \\
\hline \multicolumn{10}{|l|}{ WI (\%) } \\
\hline Mean & 558.63 & 558.63 & 1 & & & & & & \\
\hline Linear & 7.49 & 1.87 & 3 & 14.52 & 0.2483 & 0.708 & 0.659 & 0.567 & \\
\hline $2 \mathrm{FI}$ & 0.55 & 0.09 & 3 & 0.65 & 0.6928 & 0.759 & 0.626 & 0.316 & \\
\hline Quadratic & 2.49 & 0.62 & 3 & 172.31 & 0.0007 & 0.925 & 0.890 & 0.872 & Suggested \\
\hline Cubic & 0.03 & 0.00 & 2 & 1.11 & 0.4643 & 0.998 & 0.991 & 0.721 & Aliased \\
\hline Residual & 0.02 & 0.00 & 5 & & & & & & \\
\hline Total & 569.21 & 19.63 & 17 & & & & & & \\
\hline \multicolumn{10}{|c|}{ Solubility (\%) } \\
\hline Mean & 17.44 & 17.44 & 1 & & & & & & \\
\hline Linear & 1.47 & 0.49 & 3 & 0.85 & 0.0049 & 0.605 & 0.590 & 0.574 & \\
\hline $2 \mathrm{FI}$ & 2.70 & 0.90 & 3 & 1.87 & 0.0058 & 0.666 & 0.642 & 0.631 & \\
\hline Quadratic & 2.12 & 0.71 & 3 & 6.84 & 0.0002 & 0.927 & 0.914 & 0.901 & Suggested \\
\hline Cubic & 2.37 & 1.18 & 2 & 18.48 & 0.0049 & 0.911 & 0.894 & 0.873 & Aliased \\
\hline Residual & 0.32 & 0.064 & 5 & & & & & & \\
\hline Total & 26.42 & 1.55 & 17 & & & & & & \\
\hline \multicolumn{10}{|c|}{ Swelling power $(\mathrm{g} / \mathrm{g})$} \\
\hline Mean & 60.42 & 60.42 & 1 & & & & & & \\
\hline Linear & $5.708 \mathrm{E}-003$ & $1.903 \mathrm{E}-003$ & 3 & 1.89 & 0.181 & 0.303 & 0.142 & -0.377 & \\
\hline $2 \mathrm{FI}$ & $3.700 \mathrm{E}-003$ & $1.233 \mathrm{E}-003$ & 3 & 1.31 & 0.324 & 0.499 & 0.199 & -1.036 & \\
\hline Quadratic & 8.417E-003 & $2.806 \mathrm{E}-003$ & 3 & 19.67 & 0.0009 & 0.947 & 0.878 & 0.864 & Suggested \\
\hline Cubic & $2.286 \mathrm{E}-004$ & $1.143 \mathrm{E}-004$ & 2 & 0.74 & 0.522 & 0.959 & 0.869 & 0.842 & Aliased \\
\hline Residual & 7.700E-004 & $1.540 \mathrm{E}-004$ & 5 & & & & & & \\
\hline Total & 60.44 & 3.56 & 17 & & & & & & \\
\hline
\end{tabular}


Table.4 Analysis of variance of the regression coefficients of the fitted polynomial quadratic models for cassava starch properties

\begin{tabular}{|c|c|c|c|c|c|c|c|c|c|c|c|c|}
\hline \multirow[t]{2}{*}{ Source } & \multicolumn{2}{|c|}{ OC } & \multicolumn{2}{|c|}{ FT } & \multicolumn{2}{|c|}{ TCD } & \multicolumn{2}{|c|}{ WI } & \multicolumn{2}{|c|}{ SOL } & \multicolumn{2}{|c|}{ SP } \\
\hline & $\mathrm{CE}$ & $\mathrm{p}$-value & $\mathrm{CE}$ & $\mathrm{p}$-value & $\mathrm{CE}$ & $\mathrm{p}$-value & $\mathrm{CE}$ & $\mathrm{p}$-value & $\mathrm{CE}$ & $\mathrm{p}$-value & $\mathrm{CE}$ & $\mathrm{p}$-value \\
\hline Model & 10.29 & 0.0021 & 56.22 & 0.0151 & 3.39 & 0.0080 & 89.04 & 0.0065 & 0.40 & 0.0274 & 1.910 & 0.0011 \\
\hline $\mathbf{X}_{1}$ & 2.19 & 0.3786 & 0.07 & 0.9765 & -0.05 & 0.6390 & 0.038 & 0.4528 & 0.20 & 0.0100 & 0.022 & 0.0011 \\
\hline $\mathbf{X}_{2}$ & -7.13 & 0.0376 & 5.92 & 0.0969 & 0.15 & 0.3062 & 0.18 & 0.0630 & 0.086 & 0.2501 & 0.024 & 0.0023 \\
\hline $\mathbf{X}_{3}$ & 5.78 & 0.0767 & 3.25 & 0.3278 & -0.60 & 0.0018 & 0.47 & 0.3675 & 0.11 & 0.1384 & 0.026 & 0.0012 \\
\hline $\mathbf{X}_{12}$ & -10.64 & 0.0145 & 18.70 & 0.0014 & 0.24 & 0.1715 & -0.015 & 0.6797 & -0.20 & 0.0426 & -0.005 & 0.4301 \\
\hline $\mathbf{X}_{13}$ & 15.82 & 0.0020 & 4.49 & 0.2585 & 0.37 & 0.0555 & 1.27 & 0.1967 & -0.20 & 0.0426 & -0.030 & 0.0015 \\
\hline $\mathbf{X}_{23}$ & 15.96 & 0.0093 & -11.56 & 0.0533 & -0.16 & 0.4774 & -0.77 & 0.0046 & 0.029 & 0.8026 & -0.032 & 0.0055 \\
\hline $\mathrm{X}_{1}^{2}$ & -9.48 & 0.0323 & -0.01 & 0.9962 & 0.07 & 0.6945 & -0.24 & 0.1874 & 0.21 & 0.0445 & 0.016 & 0.0427 \\
\hline $\mathbf{X}_{2}^{2}$ & 12.68 & 0.0093 & -2.40 & 0.5624 & 0.01 & 0.9472 & 0.65 & 0.8522 & -0.015 & 0.8659 & -0.032 & 0.0016 \\
\hline $\mathbf{X}_{3}^{2}$ & 21.08 & 0.0006 & -18.44 & 0.0023 & 0.48 & 0.0268 & 1.46 & 0.0626 & -0.22 & 0.0430 & -0.042 & 0.0003 \\
\hline
\end{tabular}



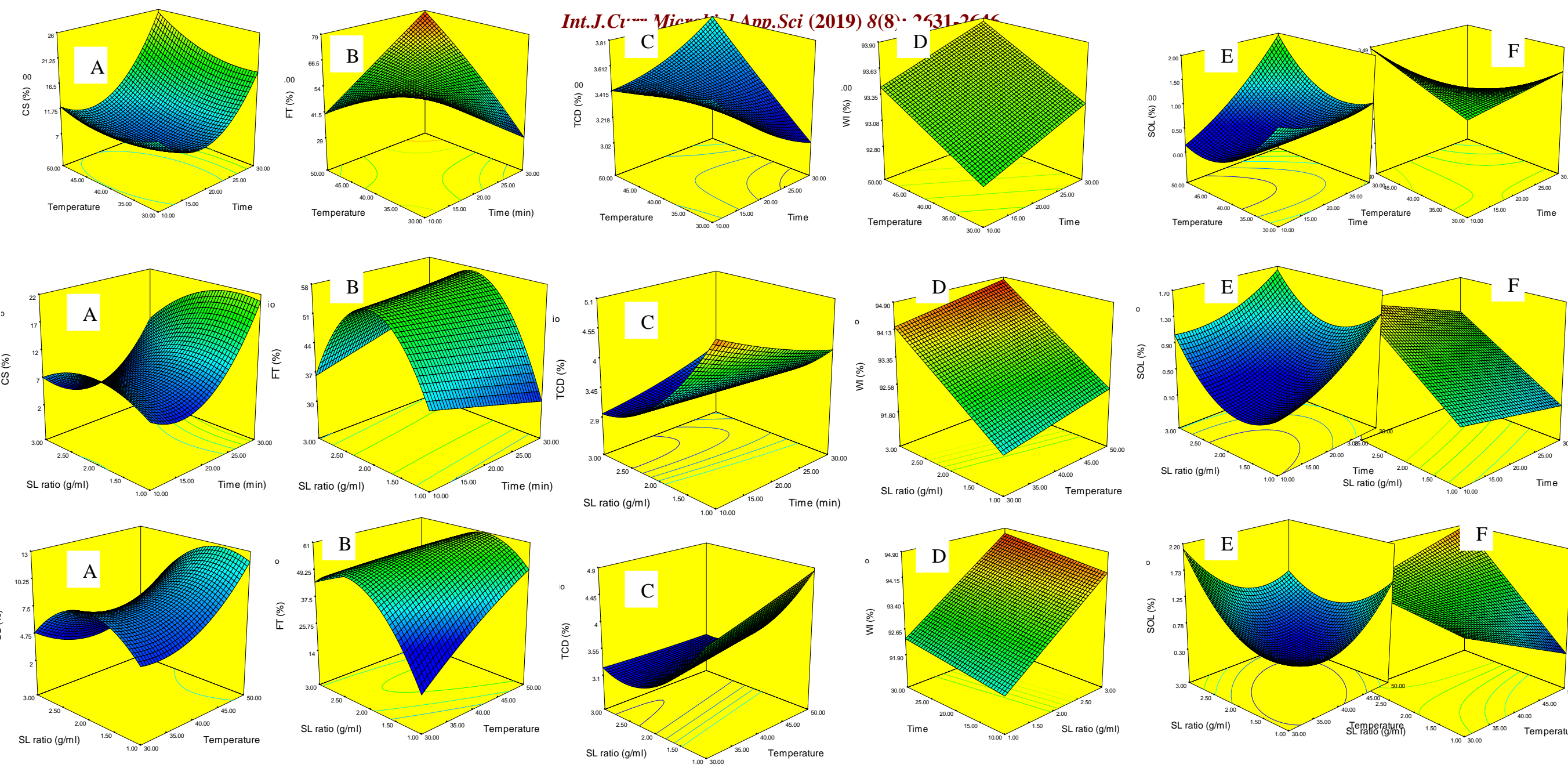

Fig.2 Response surface plot showing the effects of sonication temperature, sonication time and solid-liquid ratio on

CS (a), FT (b), TCD (c), WI (d), SOL (e), SP (f) 

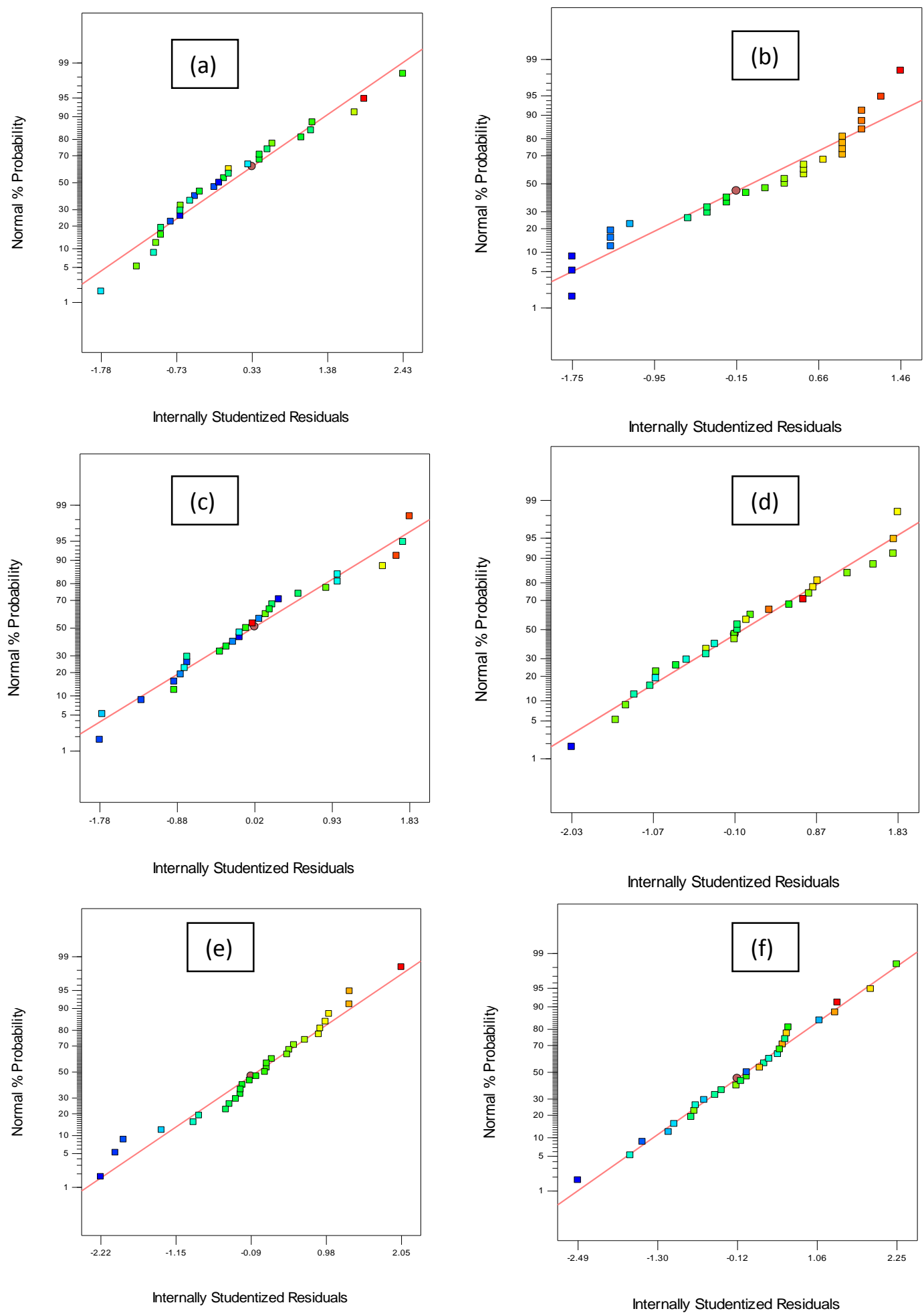

Fig.1. Normal probability plots of studentized residuals for optical clarity (a), freeze-thaw stability (b), total colour difference(c), whiteness index (d), solubility (e), swelling power (f) 

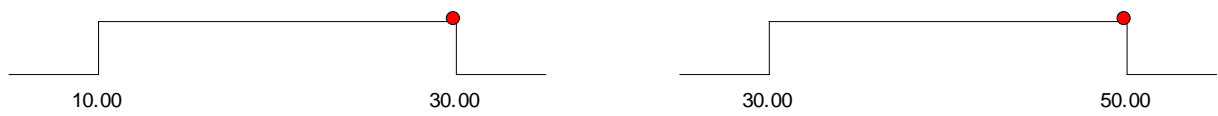

Time $=30.00$
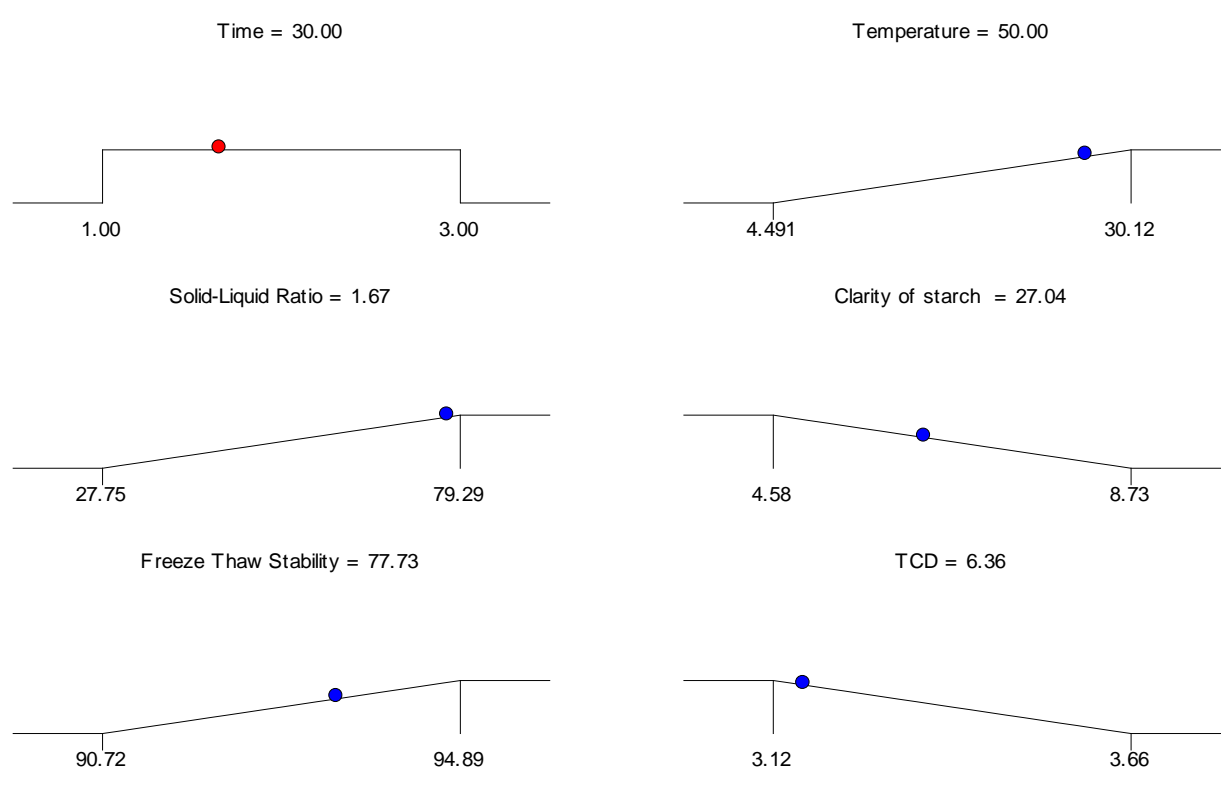

$W I=93.47$

Swelling power $=3.17$

Desirability $=0.699$

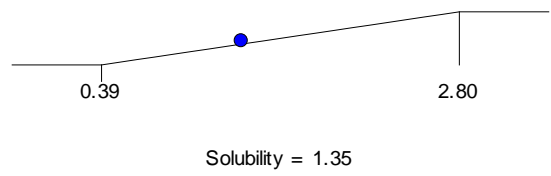

Fig.3 Desirability ramp for optimized conditions for cassava starch properties

In general, $F$ value greater than 4 is acceptable and the present models got a $\mathrm{F}$ value higher than 4 , which shows that these models are significant to predict cassava starch properties.

\section{Adequacy of the models}

Checking of model adequacy is to calculate whether the developed regression model is adequate or not and how best the developed model predicts the response. Analysis of variance was used to check the adequacy of the developed polynomial quadratic model. The diagnostic residual analysis for validating the model is presented in the Fig. 1. The predicted and the experimental data points were close enough and showed a straight line relationship, which confirms the good agreement between the experimental independent process variables and the response (Fig. 1). This clearly depicts that the developed model is successful to capture the correlation between the independent process variables on the response (OC, FT, TCD, WI, SOL, SP). The normal probability/test plot is a graphical tool suitable to determine residuals normality. The goodness of fit model is a component of regression analysis and calculated using the values of internally 
studentized residuals and normal \% probability. In this present study, all the data points were within acceptable limits as they lie on a straight line. This confirms that experimental data are normally distributed.

\section{Effect of process variables}

The various process variables (sonication power, sonication time and solid to solvent ratio) were studied on the response (OC, FT, TCD, WI, SOL, SP) in this present study. A BBD design under three variables at three levels was performed to assess the effects of experimental process variables on starch yield. To understand the interaction between the process variables and the response, a three-dimensional (3D) response surface and contour graphs were drawn by keeping the third variable constant at the " 0 " level and adjusting the other two variables. This is variably used to find out the optimal conditions. The response surface plot estimating the starch properties against independent process variables are presented in Fig.2. In this study, the potential effect of different sonication temperature $\left(30-50^{\circ} \mathrm{C}\right)$ on response (OC, FT, TCD, WI, SOL, SP) was studied. The cassava starch properties (CS, TCD, WI, SP) were increased with increase in sonication temperature, whereas cassava starch properties (FD, SOL) were decreased with increase in sonication temperature (Fig. 2). As larger ultrasound wave passed over the liquid medium, harsh shock waves and high speed jets were developed by ultrasonic waves, stimulates the swelling of matrix and increase of micro bubbles in the matrix, which permits higher diffusivity in the cassava mash and increase the starch properties (Vinatoru, 2001; Ponmurugan et al., 2017). Sonication temperature has a greater influence on cavitational effect. Sonication time is an important and highly influencing variable for extraction of the cassava starch.
The influence of sonication time on cassava starch properties was studied and the results are presented in the Fig. 2. The properties (CS, TCD, WI, SOL) were increased with increase in sonication time, whereas cassava starch properties (FT, SP) were decreased with increase in sonication time (Fig. 2). The diffusion of ultrasonic waves modifies the properties of starch (Sun and Tomkinson, 2002). Nevertheless, the penetration and heating effect of ultrasonic treatment for longer duration might cause the structural changes of starch due to frequent asymmetric collapse of micro-bubbles. SL ratio is also one of the important factors responsible for modifying starch properties. In this study, a different SL ratio ranged from 1:10 to $1: 30$ $\mathrm{g} / \mathrm{ml}$ was studied and showed that the starch properties were highly influenced by SS ratio (Fig. 2). The properties (FT, WI, SOL, SP) were increased with increase in sonication time, whereas cassava starch properties (CS, TCD) were decreased with increase in sonication time (Fig. 2). The higher ratio of solid to solvent means higher concentration difference which in turn facilitates the mass transfer rate results and yield different starch properties (Romdhane and Gourdon, 2002). However, the higher ratio of raw material to water beyond the required level would not change much of driving force (diffusion rate) furthermore as transfer of mass is mostly confined towards interior solid tissues (Zhang et al., 2008). Further, this is associated with the cavitation formation which invariably requires negative pressure in the rarefaction cycle to overcome the natural cohesive forces (Xu et al., 2014).

\section{Determination and validation of optimized conditions}

Second order polynomial models developed in this study were utilized for each response in order to obtain specified optimum conditions. To optimize the process 
conditions, derringer's desired methodology was adopted and as follows: sonication temp of $50^{\circ} \mathrm{C}$, sonication time of $30 \mathrm{~min}$, solidliquid ratio of $1: 16.7 \mathrm{~g} / \mathrm{ml}$. Under these optimum conditions, the predicted CS of $27.04 \%$, FT of $77.73 \%$, TCD of $6.36 \%$, WI of $93.47 \%$, SOL of $1.36 \%$ and SP of 3.17 $\mathrm{g} / \mathrm{g}$ with a desirability value of 0.699 . The desirability ramp for optimal points was generated by numerical optimization technique (Fig. 3). For validating the optimum extraction process conditions, confirmatory experiment in triplicates $(n=3)$ was successfully performed under the optimal conditions. The experimental efficiency of the cassava starch properties (OC, FT, TCD, WI, SOL, SP) under optimal conditions were found to be $25.10 \%$ of CS, $75.02 \%$ of FT, $4.96 \%$ of TCD, $91.16 \%$ of WI, $1.02 \%$ of SOL and $1.98 \mathrm{~g} / \mathrm{g}$ of SP respectively. The results obtained through confirmation experiments indicate the suitability of the developed quadratic models and it may be noted that these optimal values are valid within the specified range of process parameters.

In this present study, three level Box-Behnken design (BBD) with three factors was successfully used to optimize the independent process variables (sonication temperature, sonication time and solid-liquid ratio) for cassava starch properties. The design of experiments, second order polynomial nonlinear regression models and numerical optimization were performed using commercial statistical software (DesignExpert $\left.{ }^{\circledR}\right)$. BBD technique was employed to develop mathematical models for determining cassava starch properties such as optical clarity, freeze-thaw stability, total colour difference, whiteness index, solubility and swelling power. A maximum determination coefficient $\left(R^{2}>0.90\right)$, ensuring a satisfactory fit of the developed models with the experimental data. The optimal conditions to predict the cassava starch properties were determined by desired function methodology as follows; sonication temp of $50^{\circ} \mathrm{C}$, sonication time of $30 \mathrm{~min}$, solid-liquid ratio of 1:16.7 $\mathrm{g} / \mathrm{ml}$. Under optimal conditions, the experimental values were shown to be in agreement with those predicted values obtained from the developed model.

\section{Acknowledgments}

The authors are thankful to Director, ICARCTCRI, Trivandrum, Kerala for providing the research facilities to conduct this study.

\section{References}

Betancur, D. A., Ancona, L. A. C., Guerrero, R. I., Camelo Matos, G. and Ortiz, D. 2001. Physicochemical and functional characterization of baby lima bean (Phaseolus lunatus) starch. Starch- Stärke, 53(5):219-226.

C.I.E Colorimetrie. 1986. 2nd ed. Publication. C.I.E. No. 15, 2 Central Bureau of the Commission Internationale de L'Eclairage, Viena.

Derringer, G., \& Suich, R. 1980. Simultaneous optimization of several response variables. Journal of quality technology, 12(4): 214-219.

Ding, Q., Ainsworth, P., Plunkett, A., Tucker, G. and Marson, H. 2006. The effect of extrusion conditions on the functional and physical properties of wheat-based expanded snacks. Journal of Food Engineering, 73 (2), 142-148.

Hatambeygi, N., Abedi, G. and Talebi, M., 2011. Method development and validation for optimized separation of salicylic, acetyl salicylic and ascorbic acid in pharmaceutical formulations by hydrophilic interaction chromatography and response surface methodology. $J$. Chromatogr. A 1218: 5995-6003.

Jambrak, A. R., Herceg, Z., Šubarić, D., 
Babić, J., Brnčić, M., Brnčić, S. R. and Gelo, J. 2010. Ultrasound effect on physical properties of corn starch. Carbohydrate Polymers, 79(1): 91-100.

Krishnakumar, T. and Sajeev, M.S. 2017. Response surface optimization of bath type ultrasound-assisted extraction (UAE) of native starch from fresh cassava tubers. Advances in Research 12(3): 1-13.

Krishnakumar, T. and Sajeev, M.S. 2018. Effect of ultrasound treatment on physicochemical and functional properties of cassava starch. Int. J.curr.Microbiol.App.Sci. $\quad$ 7(10):31223135.

Krishnakumar. T., Ashish Rawson, Sheriff, J.T., Sajeev, M.S. and Thamilselvi.C. 2016. In: Optimization of ultrasound assisted extraction of starch from cassava. S.K.Das, A.K.Datta, T.K.Goswami, P.S.Rao (Eds.). Excel India Publishers, New Delhi. India, pp. 210-219.

Li, Y., Guo, C., Yang, J., Wei, J., Xu, J. and Cheng, S. 2006. Evaluation of antioxidant properties of pomegranate peel extract in comparison with pomegranate pulp extract. Food Chemistry, 96 (2): 254-260.

Ma, T., Sun, X., Tian, C., Luo, J., Zheng, C. and Zhan, J. 2016. Polysaccharide extraction from Sphallerocarpus gracilis roots by response surface methodology. International Journal of Biological Macromolecules, 88:162170.

Ponmurugan, K., Al-Dhabi, N. A., Maran, J. P., Karthikeyan, K., Moothy, I. G., Sivarajasekar, N., \& Manoj, J. J. B. 2017. Ultrasound assisted pectic polysaccharide extraction and its characterization from waste heads of Helianthus annus. Carbohydrate polymers, 173: 707-713.
Romdhane, M. and Gourdon, C. 2002. Investigation in solid-liquid extraction: influence of ultrasound. Chemical Engineering Journal, 87 (1): 11-19.

Sandhu, K.S. and Singh, N. (2007). Some properties of corn starches II: physicochemical, gelatinization, retrogradation, pasting and gel textural properties. Food Chemistry, 101:14991507.

Sheriff, J.T., Nanda, S.K. and Sajeev, M.S. 2005. Current Status of Cassava Processing Industries in South India. Technical Bulletin No. 42. Central Tuber Crops Research Institute, Sreekariyam, Thiruvananthapuram, Kerala, India.

Singhal, R.S. and Kulkarni, P.R. 1990. Some properties of Amaranthus paniculatas (Rajgeera) starch pastes. Starch/Stärke 42:5-7.

Sun, R. and Tomkinson, J., 2002. Comparative study of lignins isolated by alkali and ultrasound-assisted alkali extractions from wheat straw. Ultrason Sonochem., 9:85-93.

Talebpour, Z., Ghassempour, A., Abbaci, M., and Aboul-Enein, H.Y. 2009. Optimization of microwave-assisted extraction for the determination of glycyrrhizin in menthazin herbal drug by experimental design methodology. Chromatographia, 70:191-197.

Vinatoru, M. 2001. An overview of the ultrasonically assisted extraction of bioactive principles from herbs. Ultrason Sonochem. 8:303-313.

Vroman, I. and Tighzert, L. 2009. Biodegradable polymers. Materials, 2(2), 307-344.

Xu, Y., Zhang, L., Bailina, Y., Ge, Z., Ding, T., Ye, X. and Liu, D. 2014. Effects of ultrasound and/or heating on the extraction of pectin from grape fruit peel. J Food Eng. 126:72-81.

Yuan, J., Huang, J., Wu, G., Tong, J., Xie, G., 
Duan, J.A. and Qin, M. 2015. Multiple responses optimization of ultrasonicassisted extraction by response surface methodology (RSM) for rapid analysis of bioactive compounds in the flower head of Chrysanthemum morifolium Ramat. Industrial Crops and Products, 74:192-199.

Zhang, Z. S., Wang, L. J., Li, D., Jiao, S. S., Chen, X. D., and Mao, Z. H. 2008.
Ultrasound-assisted extraction of oil from flaxseed. Separation and Purification Technology, 62(1):192198.

Zhu, F. 2015. Impact of ultrasound on structure, physicochemical properties, modifications, and applications of starch. Trends in Food Science \& Technology, 43(1):1-17.

\section{How to cite this article:}

Krishnakumar T., M. S. Sajeev, Namrata A. Giri, Chintha Pradeepika and Venkatraman Bansode. 2019. Development of Mathematical Model for Cassava Starch Properties Using Response Surface Methodology. Int.J.Curr.Microbiol.App.Sci. 8(08): 2631-2646.

doi: https://doi.org/10.20546/ijcmas.2019.808.306 